\title{
LINE BALANCING DENGAN METODE RANKED POSITION WEIGHT ( RPW)
}

\author{
Ita purnamasari, Atikha Sidhi Cahyana \\ Program Studi Teknik Industri \\ Universitas Muhammadiyah Sidoarjo \\ Ip@ecco.com, atikhasidhi@umsida.ac.id
}

\begin{abstract}
ABSTRAK
Persaingan antar perusahaan tidak mencakup kawasan regional dan global, oleh karena itu setiap perusahaan berlomba untuk terus menerus mencari usaha dan cara untuk mampu bersaing dan memiliki keunggulan kompetitif agar tetap hidup dan berkembang. Inilah globalisasi dan akibatnya dalam persaingan. Persaingan ini harus di dukung oleh kelancaran proses produksi dalam perusahan itu sendiri. Ranked position weigth (RPW) merupakan proses mengidentifikasi kegagalan dalam suatu proses produksi dan menetukan bobot-bobot dari proses produksi. Penentuan dari beberapa komponen yaitu dengan menetukan waktu baku, waktu normal, dan waktu siklus. Setelah ketiga komponen tersebut di hitung dan di tentukan bobot-bobot dari masing-masing proses, maka dengan mengunakan metode rpw ini di dapatkan hasil yang semula dalam proses produksi membutuhkan 20 operator dan output 700 pairs per shift dengan jumlah 24 stasiun, setelah di hitung dengan rpw maka mendapatkan jumlah yang sangat berbeda dari proses sebelumya yaitu operator hanya membutuhkan 13 dan dengan menghasilkan output yang sama yaitu 700 pairs per shift.
\end{abstract}

Kata kunci : Line balancing ,Rpw

\section{PENDAHULUAN}

Daya saing pada perusahaan manufaktur semakin ketat, setiap perusahaan akan berusaha semaksimal mungkin untuk terus menerus melakukan peningkatan kualitas dan kuantitas produksinya supaya terus mendapat kepercayaan dari para konsumennya. PT. XYZ merupakan perusahaan yang bergerak di bidang manufaktur yang membuat sepatu. Selama ini sering dijumpai hambatan (bottleneck) pada aliran proses finishing, pengalokasian stasiun-stasiun kerja yang kurang sempurna karena masih terdapat pembagian kerja yang tidak merata keoperasi-operasi kerja diproses finishing, Oleh sebab itu lintasan produksi yang ada saat ini perlu diseimbangkan supaya dapat mengurangi atau menghilangkan delay dan line menjadi lebih efektif dan efisien, setiap line yang baru memproduksi article baru pasti mengalami bottleneck, sehinga flow tidak lancar untuk mengatasi masalah itu maka team work study menganalisa dan mengambil tindakan hari itu juga. Dengan mengunakan metode ranked positional weight $(R P W)$ yang berbasis akumulasi, waktu penyelesaian task ini merupakan metode yang menemukan solusi dengan cepat.

\section{LANDASAN TEORI}

\section{A. line balancing}

Menurut Gaspersz (2004), Line balancing merupakan penyimbangan penugasan elemen tugas dari suatu assembly line ke work stations untuk meminimumkan banyaknya work stations dan meminimumkan total harga idle time pada semua stasiun untuk tingkat output tertentu. Dalam penyeimbangan tugas ini,kebutuhan waktu per unit produk yang dispesifikasikan dan di perhitungkan. Adapun tanda-tanda yang dipakai sebagai berikut : (a). Simbol lingkaran dengan huruf atau nomor di dalamnya untuk mempermudah identifikasi dari suatu proses operasi. (b). Tanda panah menunjukkan ketergantungan dan urutan proses operasi. Dalam hal ini, operasi yang berada pada pangkal panah berarti mendahului operasi kerja yang ada pada ujung anak panah. (c). 
Angka di atas simbol lingkaran adalah waktu standar yang diperlukan untuk menyelesaikan setiap operasi

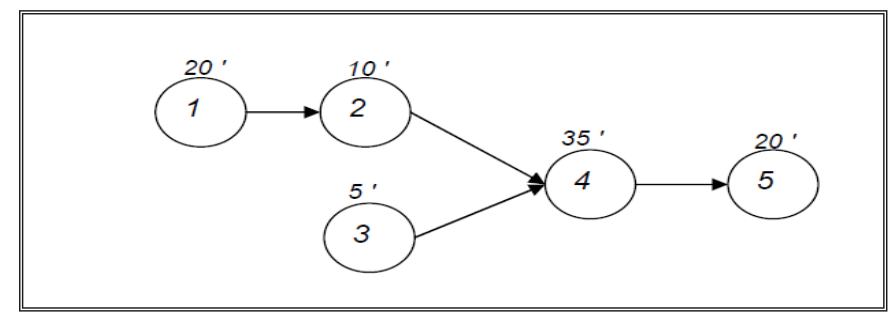

Gambar 1. Contoh Precedence Diagram ( sumber : Baroto, 2002 )

\section{B. Waktu Menganggur (Idle Time)}

Idle time adalah selisih atau perbedaan antara Cycle Time (CT) dan Stasiun Time (ST), atau CT dikurangi ST ( sumber : Baroto dari Evi, 2013 ) :

$$
\text { Idle Time }=\mathrm{n} . \mathrm{Ws}-{\underset{\mathrm{i}=1}{\mathrm{n}} \mathrm{Wi}}^{\mathrm{n}}
$$

Keterangan:

$$
\begin{array}{ll}
\mathrm{n} & =\text { Jumlah stasiun kerja. } \\
\mathrm{Ws} & =\text { Jumlah stasiun kerja terbesar. } \\
\mathrm{Wi} & =\text { Waktu sebenarnya pada stasiun kerja. } \\
\mathrm{i} & =1,2,3, \ldots, \mathrm{n}
\end{array}
$$

\section{Keseimbangan Waktu Senggang (Balance Delay)}

Balance Delay merupakan ukuran dari ketidakefisienan lintasan yang dihasilkan dari waktu mengganggur sebenarnya yang disebabkan karena pengalokasian yang kurang sempurna di antara stasiun-stasiun kerja. Balance Delay dapat dirumuskan sebagai berikut (Sumber : Baroto dari Evi, 2013) :

$$
D=\frac{n \cdot C-t_{i}}{\left(n \cdot t_{i}\right)} \times 100
$$

Keterangan:

$$
\begin{array}{ll}
\mathrm{D} & =\text { Balance Delay }(\%) \\
\mathrm{n} & =\text { Jumlah stasiun kerja } \\
\mathrm{C} & =\text { Waktu siklus terbesar dalam stasiun kerja } \\
\sum_{\mathrm{t}} \mathrm{t}_{\mathrm{i}} & =\text { Jumlah semua waktu operasi } \\
\mathrm{t}_{\mathrm{i}} & =\text { Waktu operasi }
\end{array}
$$

\section{Efisiensi Stasiun Kerja}

Efisiensi stasiun kerja merupakan rasio antara waktu operasi tiap stasiun kerja (Wi) dan waktu operasi stasiun kerja terbesar (Ws). Efisiensi stasiun kerja dapat dirumuskan sebagai berikut ( Sumber : Nasution dari Evi,2003) :

$$
\text { Efisiensi Stasiun Kerja }=\frac{\mathbf{W}_{\mathbf{i}}}{\mathbf{W}_{\mathrm{s}}} \times 100 \%
$$

Keterangan:

$\mathrm{Wi}=$ Waktu sebenarnya pada stasiun kerja.

Ws = Jumlah stasiun kerja terbesar. 


\section{E. Efisiensi Lintasan Produksi (Line Efficiency).}

Line Efficiency merupakan rasio dari total waktu stasiun kerja dibagi dengan siklus dikalikan jumlah stasiun kerja atau jumlah efisiensi stasiun kerja dibagi jumlah stasiun kerja.

Line efficiency dapat dirumuskan sebagai berikut (Sumber : Baroto dari Evi,2013):

$$
\text { Line Efficiency }=\frac{\underset{i=1}{k} S T_{i}}{K(C T)} \times 100
$$

Keterangan :

$$
\begin{array}{ll}
\mathrm{STi} & =\text { Waktu stasiun kerja dari ke-i } \\
\mathrm{K} & =\text { Jumlah stasiun kerja } \\
\mathrm{CT} & =\text { Waktu siklus }
\end{array}
$$

\section{F. Smoothest Indeks}

Smoothet Indeks merupakan indeks yang menunjukkan kelancaran relatif dari penyeimbangan lini perakitan tertentu (sumber : Dyah, 2005 )

$$
S I=\overline{i_{i=1}^{k}(C T \max -S T i)^{2}}
$$

Keterangan :

SI $\quad=$ Smoothest Indeks

ST $\max =$ Maksimum waktu di stasiun

\section{G. Work Station}

Work Station merupakan tempat pada lini perakitan di mana proses perakitan dilakukan. Setelah menentukan interval waktu siklus, maka jumlah stasiun kerja yang efisien dapat ditetapkan dengan rumus ( sumber : Baroto, 2002)

Keterangan :

$$
K \min =\frac{\substack{k \\ i=1}}{C}
$$

ti $\quad=$ Waktu operasi (elemen)

$\mathrm{C} \quad=$ Waktu siklus stasiun kerja

$\mathrm{K} \min =$ Jumlah stasiun kerja minimal

\section{H. Definisi ranked positional weight ( RPW)}

Metode Rangked Positional Weights (RPW) Metode ini merupakan metode gabungan antara metode Large Candidat Ruler dengan metode region approach. nilai $R P W$ merupakan perhitungan antara elemen kerja tersebut dengan posisi masing-masing elemen kerja dalam precedence diagram. Langkah-langkah dari metode RPW adalah sebagai berikut (Heizer dan Render, 2006):

1. Membuat precedence diagram atau diagram jaringan kerja dari OPC

2. Menghitung waktu siklus

3. Membuat matiks lintasan berdasarkan precedence diagram.

4. Menghitung bobot posisi tiap operasi yang dihitung berdasarkan jumlah waktu operasi tersebut dan operasi-operasi yang mengikutinya

5. Mengurutan operasi-operasi mulai bobot operasi terbesar sampai dengan terkecil

6. Menghitung jumlah stasiun kerja minimum

7. Membuat flow diagram untuk stasiun kerja minimum tersebut lalu lakukan pembebanan operasi pada stasiun kerja mulai dari operasi dari bobot operasi 
terbesar sampai dengan terkecil, dengan kriteria total waktu operasi lebih kecil dari waktu siklus yang diinginkan

8. Melakukan trial and error untuk mendapatkan efisiensi lintasan yang paling tinggi.

9. Menghitung balance delay lintasan

\section{Perhitungan Ranked Positional Weight (RPW)}

Waktu Normal :

Adalah waktu yang dibutuhkan oleh operator untuk memproduksi secara normal.

$$
\mathrm{WN}=\mathrm{WS} \times \mathrm{P}
$$

Waktu Baku :

Adalah waktu yang dibutuhkan untuk melakukan pekerjaan secara standart.

$$
W B=W N \times \frac{100 \%}{100 \%-\% \text { Allowance }}
$$

Waktu Mengganggur dan Waktu Efektif :

$$
\begin{aligned}
& \mathrm{WM}=480 \times \text { Allowance } \\
& \mathrm{WE}=480-\mathrm{WM}
\end{aligned}
$$

\section{Output Standart :}

Adalah waktu yang dibutuhkan untuk menghasilkan suatu produk.

$$
\text { OS }=\frac{1}{W B}
$$

Waktu siklus :

Adalah waktu yang dibutuhkan untuk memproduksi suatu produk (Nasution, 2003).

$$
\mathrm{WS}=\bar{x}=\frac{\sum x_{i}}{n}
$$

\section{J. Penelitian terdahulu}

Tabel 1. Penelitian terdahulu

\begin{tabular}{|l|l|l|l|l|l|}
\hline No & \multicolumn{1}{|c|}{ Nama } & Tahun & \multicolumn{1}{c|}{ Judul } & Metode & \multicolumn{1}{c|}{ Hasil } \\
\hline 1 & $\begin{array}{l}\text { Yayan } \\
\text { Indrawan }\end{array}$ & 2003 & $\begin{array}{l}\text { Minimalisasi } \\
\text { bottleneck } \\
\text { proses produksi }\end{array}$ & $\begin{array}{l}\text { Line } \\
\text { balancing }\end{array}$ & $\begin{array}{l}\text { Meningkatkan output produksi } \\
\text { sebesar 37/ton dari 400 ton } \\
\text { /bulan menjadi 437 ton/bulan. }\end{array}$ \\
\hline 2 & $\begin{array}{l}\text { Dyah } \\
\text { Saptnti } \\
\text { Perwitasari }\end{array}$ & 2005 & $\begin{array}{l}\text { Permasalahan } \\
\text { keseimbangan } \\
\text { lini lintasan } \\
\text { Produksi } \\
\text { berbasi single } \\
\text { model. }\end{array}$ & $\begin{array}{l}\text { RPW \& } \\
\text { KW }\end{array}$ & $\begin{array}{l}\text { Metode RPW lebih unggul dari } \\
\text { pada metode KW, sedangkan } \\
\text { dari segi algoritma,sulit untuk } \\
\text { menyimpulkan karena hampir } \\
\text { sama. }\end{array}$ \\
\hline 3 & Evi vebianti & 2013 & $\begin{array}{l}\text { Perbaikan } \\
\text { perencanaan } \\
\text { produksi dengan }\end{array}$ & $\begin{array}{l}\text { Line } \\
\text { balancing } \\
\&\end{array}$ & $\begin{array}{l}\text { Dari hasil penelitian di peroleh } \\
\text { jumlah stasiun yang optimal } \\
\text { adalah 3 stasiun. }\end{array}$ \\
\hline
\end{tabular}




\begin{tabular}{|l|l|l|l|l|l|}
\hline & & $\begin{array}{l}\text { pendekatan line } \\
\text { balancing dan } \\
\text { penjadwalan } \\
\text { batch }\end{array}$ & $\begin{array}{l}\text { penjadwal } \\
\text { an batch. }\end{array}$ & \\
\hline 4 & $\begin{array}{l}\text { Engilana } \\
\text { C.Dengah }\end{array}$ & 2013 & $\begin{array}{l}\text { Program } \\
\text { komputasi RPW } \\
\text { untuk } \\
\text { keseimbangan } \\
\text { lintasan } \\
\text { perakitan }\end{array}$ & $\begin{array}{l}\text { Line balancing } \\
\text { dengan } \\
\text { mengunakan } \\
\text { metode RPW }\end{array}$ & $\begin{array}{l}\text { Perbandingan jumlah stasiun } \\
\text { kerja,penugasan element kerja } \\
\text { di setiap stasiun,dan efisiensi } \\
\text { keseimbangan lintasan untuk 3 } \\
\text { waktu siklus yang berbeda. }\end{array}$ \\
\hline 5 & $\begin{array}{l}\text { Ita } \\
\text { purnamasari }\end{array}$ & 2014 & $\begin{array}{l}\text { memaksimalkan efisiensi dan } \\
\text { meminimumkan } \\
\text { keterlambatan }\end{array}$ \\
\hline
\end{tabular}

\section{METODOLOGI PENELITIAN}

Dalam melakukan suatu pengolahan data, diperlukan suatu tahapan-tahapan dalam penghitungannya baik penghitungan dengan metode Ranked positional weight $(R P W)$. Tahapan-tahapan tersebut adalah :

\section{a. Time study langsung dengan metode RPW}

1. Menentukan waktu siklus.

2. Menentukan waktu normal.

3. Menentukan waktu baku.

4. Menentukan waktu menggangur dan waktu Efektif.

5. Menentukan output standart.

b. Time study secara tidak langsung dengan metode RPW

1. Menetapkan periode pengukuran dan criteria Line Balancing.

2. Menentukan tingkat pencapaian performance.

3. Membentuk kerangka model $R P W$ dan menentukan indikator pencapaiannya.

Data-data yang telah di peroleh dari data primer dan sekunder akan diolah dengan cara:

1. Membuat precedence diagram atau diagram jaringan kerja dari OPC

2. Membuat matiks lintasan berdasarkan precedence diagram.

3. Menghitung bobot posisi tiap operasi yang dihitung berdasarkan jumlah waktu operasi tersebut dan operasi-operasi yang mengikutinya

4. Mengurutan operasi-operasi mulai bobot operasi terbesar sampai dengan terkecil

5. Menghitung jumlah stasiun kerja minimum

6. Membuat flow diagram untuk stasiun kerja minimum tersebut lalu lakukan pembebanan operasi pada stasiun kerja mulai dari operasi dari bobot operasi terbesar sampai dengan terkecil, dengan kriteria total waktu operasi lebih kecil dari waktu siklus yang diinginkan

7. Melakukan trial and error untuk mendapatkan efisiensi lintasan yang paling tinggi.

8. Menghitung balance delay lintasan

c. Analisa dan Pembahasan

Dalam tahap analisa dan pembahasan dijelaskan tentang hasil pengolahan data yang terdiri dari :

1. Data cycle time proses produksi di finishing untuk mendapatkan nilai efisiensi dengan metode $R P W$.

2. Data operation time pada area finishing untuk mendapatkan nilai Ratting dan nilai dalam suatu proses dengan metode $R P W$.

3. Melakukan analisa penghitungan nilai suatu proses di finishing agar menghasilkan line yang balancing dengan memaksimalkan jumlah operator. 
4. Identifikasi permasalahan dari bottle neck yang ada di area finishing.

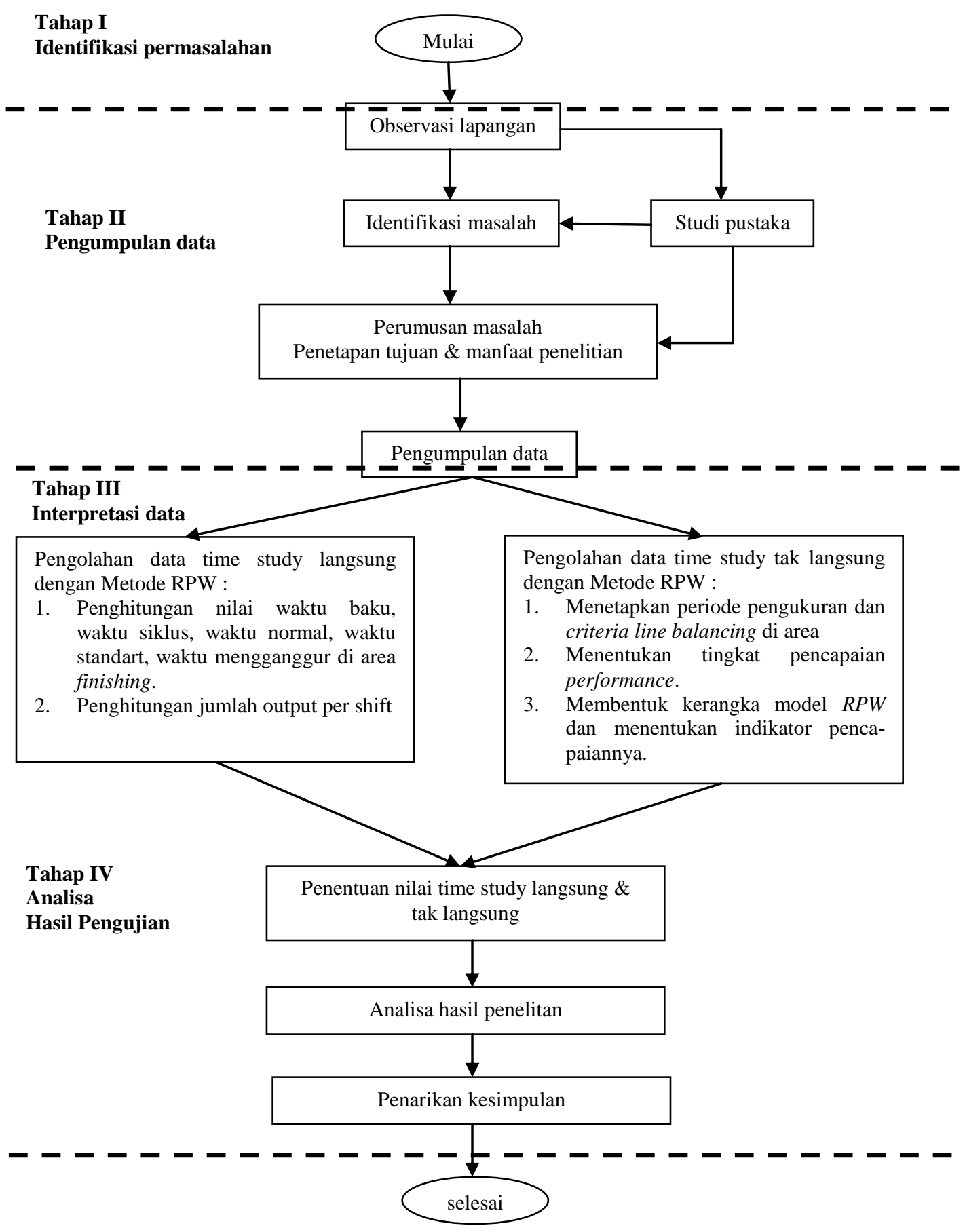

Gambar 2. Flowchart metodologi penelitian

\section{HASIL DAN PEMBAHASAN}

\section{A. Pengumpulan data}

Data yang di gunakan dalam penelitian ini dari group article cairo terdiri atas beberapa operasi kerja diantaranya, hand ironning, hot blow, creaming hand ironing , brushing upper dll.

Cara mendapatkan data dengan melakukan observasi di area produksi adapun data2 proses dan komponen 2 adalah sebagai berikut : 
Pengumpulan informasi dan fungsi komponen - komponen Proses :

1. Hand ironning

Fungsi operasi ini adalah untuk menghaluskan kulit yang berkerut karena proses proses di area injection misal lasting, injec, delasting dan lain - lain.

2. Hot blow

Fungsi proses ini adalah Untuk menghaluskan atau meratakan kulit seperti pada proses no 1, tetapi dengan proses ini bagian-bagian terkecil bisa terjangkau.

3. Creaming

Fungsi proses ini adalah Untuk memberikan sentuhan efek warna yang natural sehingga sepatu kelihatan lebih bagus.

4. Hand Ironing

Fungsi proses ini adalah Untuk menghaluskan kulit setelah proses creaming sehingga creaming merasuk kedalam pori2 dan menjadi lebih natural .

5. Lem sepatu dan alas kaki

Fungsi dari operasi ini adalh untuk menempelkan alas sepatu dengan sepatu sehingga ketika di pakai tidak lepas.

\section{B. Bahan - Bahan yang di gunakan}

Bahan - bahan yang di gunakan untuk proses - proses pembuatan sepatu di area finishing adalah sebagai berikut:

1. Cream burnosealler

2. Wax abraluk netral

3. Lem $98 \mathrm{Nh}$

4. Cream 4019 A + DEE 1010

5. Cream $4019 A$

6. Wax seracarna

7. $\mathrm{Se} 1423$

\section{Mesin-mesin dan alat yang di gunakan}

Alat-alat yang di gunakan dalam proses pembuatan sepatu di area finishing :

1. Hand ironing mesin

2. Hot blow $m c$

3. Hand ironing $m c$

4. Brushing $m c$

5. Gunting,cutter

6. Cabin spray $m c$

7. Spray gun $m c$

D. Uji keseragaman data pada proses creaming upper

Maka di peroleh keseragaman data sbb :

$$
\begin{aligned}
& \mathrm{SD}=\frac{\overline{\sum\left(\mathrm{X}_{1}-\mathrm{X}\right)^{2}+\ldots \ldots \ldots \ldots . \Sigma\left(\mathrm{X}_{\mathrm{n}}-\mathrm{X}\right)^{2}}}{\mathrm{n}-1} \\
& \mathrm{SD}=\overline{\frac{(0,558-0,553)^{2}+\ldots+(0,559-0,553)^{2}}{10-1}} \\
& \mathrm{SD}=\frac{\overline{0,0306}}{9} \\
& \mathrm{SD}=0,058
\end{aligned}
$$

Maka :

$$
\begin{aligned}
& \mathrm{BKA}=\mathrm{X}+(\mathrm{k} \times \mathrm{SD}) \\
& \mathrm{BKA}=0,553+2 \times 0,058 \\
& \mathrm{BKA}=0,719
\end{aligned}
$$




$$
\begin{aligned}
\mathrm{BKB} & =\mathrm{X}-(\mathrm{k} \times \mathrm{SD} \\
\mathrm{BKB} & =0,553-(2 \times 0,058) \\
\mathrm{BKB} & =0,437
\end{aligned}
$$

Menentukan Kecukupan data pada proses creaming satu. Maka di peroleh kecukupan data seperti di bawah ini :
a. Tinggkat kepercayaan $=95 \%$
b. Tinggkat ketelitian $=5 \%$
c. $\mathrm{S}$
$=0.005$
d. Derajat kebebasan $(\mathrm{k}) \quad=2$
e. $\mathrm{N}$
$=10$
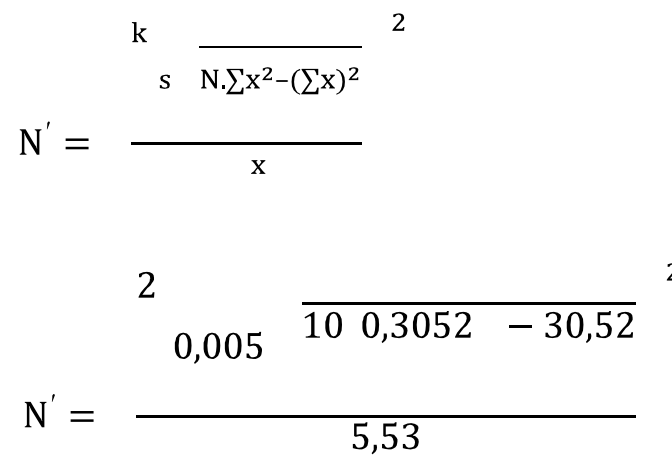

$$
\begin{array}{ll}
\mathrm{N}^{\prime} & =\frac{40 \overline{3,052-30,52}^{2}}{5,53} \\
\mathrm{~N}^{\prime} & =\frac{40 \overline{-27,48}^{2}}{5,53} \\
\mathrm{~N}^{\prime} & =\frac{40 \times 5,24^{2}}{5,53} \\
\mathrm{~N}^{\prime} & =37,90^{2} \\
\mathrm{~N}^{\prime}=1,436
\end{array}
$$

Jadi $\mathrm{N}^{\prime}=1,436$ dan $\mathrm{N}=10$, jika $\mathrm{N}>\mathrm{N}^{\prime}$ maka data sample sudah memenuhi (cukup). Karena hasil perhitungan data menunjukan $\mathbf{N}>\mathbf{N}$ ' senilai $10>1,436$ maka data sample tersebut Sudah Memenuhi (Cukup).

Tabel 2. Kecukupan data

\begin{tabular}{|c|c|c|c|}
\hline Pengamatan ke N & WAKTU & BKA & BKB \\
\hline Ke 1 & 0,558 & 0.719 & 0.437 \\
\hline Ke 2 & 0.522 & 0.719 & 0.437 \\
\hline Ke 3 334 & 0.595 & 0.719 & 0.437 \\
\hline Ke 5 & 0.545 & 0.719 & 0.437 \\
\hline Ke 6 & 0.560 & 0.719 & 0.437 \\
\hline Ke 7 & 0.526 & 0.719 & 0.437 \\
\hline Ke 8 & 0.578 & 0.719 & 0.437 \\
\hline Ke 9 & 0.541 & 0.719 & 0.437 \\
\hline Ke 10 & 0.543 & 0.719 & 0.437 \\
\hline
\end{tabular}

Menentukan waktu siklus pada stasiun kerja pada setiap stasiun.

Proses cek size + Take label 


$$
\begin{aligned}
W s & =\frac{\sum \mathrm{X}}{\mathrm{n}} \\
\mathrm{Ws} & =\frac{0,640}{10} \\
\mathrm{Ws} & =0,064 \text { menit }
\end{aligned}
$$

Menentukan waktu normal

$$
\begin{aligned}
\text { Waktu Normal } & =\text { WS } \times \text { pr } \\
& =0,064 \times 1,1
\end{aligned}
$$

Menentukan Waktu baku proses Cek size + Take label

Diketahui: Allowance $=15 \%$

$$
\begin{aligned}
\mathrm{Wb}=\mathrm{Wn} \times \frac{100 \%}{100 \%-\text { Allowance }} \begin{array}{r}
\mathrm{Wb}=0,054 \times \frac{100 \%}{100 \%-15 \%} \\
\mathrm{~Wb}=0,064 \times 1,176
\end{array} \\
\mathrm{~Wb}=0,075 \text { menit }=0,012 \text { jam,070 menit }
\end{aligned}
$$

Tabel 3. Urutan operasi berdasarkan waktu operasi

\begin{tabular}{|c|c|c|c|}
\hline \multicolumn{2}{|c|}{ Sebelum } & \multicolumn{2}{|c|}{ Sesudah } \\
\hline Urutan proses & jumlah & Urutan proses & Jumlah \\
\hline 1 & 14,758 & 1 & 14,758 \\
\hline 2 & 10.68 & 2 & 10.68 \\
\hline 3 & 9.828 & 3 & 9.828 \\
\hline 4 & 9.092 & 4 & 9.092 \\
\hline 5 & 8.539 & 5 & 8.539 \\
\hline 6 & 7.681 & 6 & 7.681 \\
\hline 7 & 6.936 & 7 & 6.936 \\
\hline 8 & 6.602 & 8 & 6.602 \\
\hline 9 & 6.454 & 9 & 6.454 \\
\hline 10 & 6.131 & 10 & 6.131 \\
\hline 11 & 5.393 & 11 & 5.393 \\
\hline 12 & 4.668 & 12 & 4.668 \\
\hline 13 & 3.941 & 13 & 3.941 \\
\hline 14 & 3.388 & 14 & 3.388 \\
\hline 15 & 3.193 & 15 & 3.193 \\
\hline 16 & 2.133 & 16 & 2.133 \\
\hline 17 & 1.898 & 17 & 1.898 \\
\hline 18 & 1.702 & 18 & 1.702 \\
\hline 19 & 1.184 & 19 & 1.184 \\
\hline
\end{tabular}

Gambar 3 menjelaskan tentang peta alur proses produksi setelah di hitung dengan mengunakan metode $R P W$.

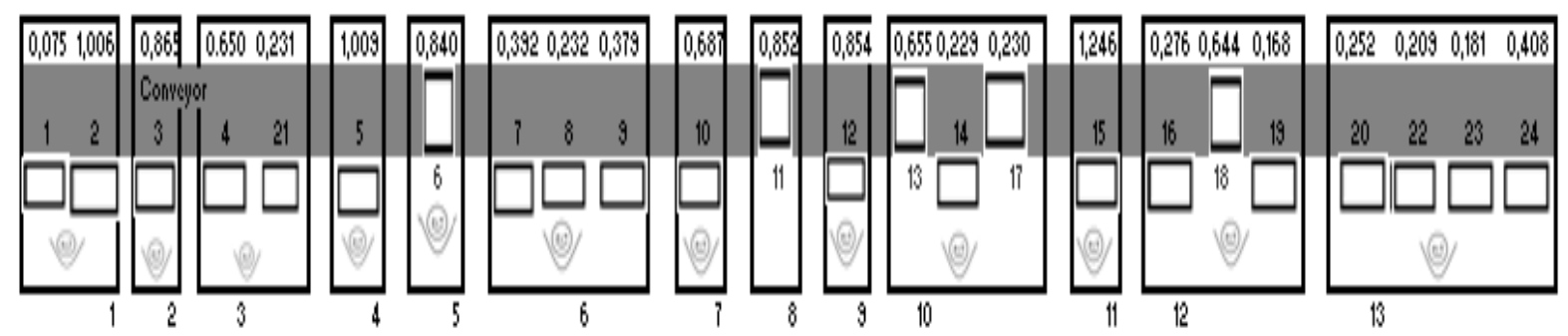

Gambar 3. Peta alur proses produksi

Perhitungan pembanding

Diketahui: Allowance $=15 \%$ 


$$
\begin{array}{r}
\mathrm{Wb}=\mathrm{Wn} \times \frac{100 \%}{100 \%-\text { Allowance }} \\
\mathrm{Wb}=0,614 \times \frac{100 \%}{100 \%-15 \%} \\
\mathrm{~Wb}=0,614 \times 1,176
\end{array}
$$

Output standart area produksi

$$
\begin{aligned}
& \text { OS }=\frac{1}{\mathrm{~Wb}}=\frac{1}{0,0112} \\
& \text { OS }=89 \text { pairs } / \text { jam. }
\end{aligned}
$$

Jadi output per jam dari proses produksi setelah di hitung dengan metode rpw article cairo adalah 89 pairs . Dan membutuhkan 13 operator dengan 13 stasiun kerja.

\section{KESIMPULAN DAN SARAN}

\section{A. Kesimpulan}

Berdasarkan hasil analisa dari pembahasan yang telah di lakukan maka dapat di proleh beberapa kesimpulan yaitu, Berdasarkan kegiatan dan interval line balancing ada beberapa operasi yang tidak efisien dan seimbang sehingga mengakibat bottle neck diarea proses tersebut :

1. Dari hasil mengidentifikasi proses - proses tersebut di temukan beberapa operasi yang tidak seimbang di antaranya cek size 0,075, Lacing 1,246, dan lain - lain .

2. Dari pengitungan telah di ketahui penyebab dan penghambat line yang tidak efisien yaitu banyak pengalokasian operator yang tidak sesuai dengan bobot dari setiap proses tersebut.

3. Setelah melakukan penghitungan dengan metode $R P W$ maka di dapat nilai - nilai dalam suatu proses yang bisa di gabug dengan proses lain atau di seimbangakan sehingga line menjadi lebih efektif dan efisien yaitu dengan menetukan bobot dari masing - masing proses, sehingga terdapat solusi yaitu di temukan beerapa proses yang di gabung sehingga dalam proses tersebut mendapatkan hasil yang cukup baik yaitu, jumlah operator yang awal 20 operator menjadi 13 operator, dan jumlah

B. Saran stasiun kerja yang awalnya membutuhkan 20 stasiun menjadi 13 stasiun kerja.

Setelah melakukan penelitian Line balancing pada departemen finishing secara teoritis mengevaluasi faktor -faktor yang menyebabkan terjadinya bottle neck pada proses produksi PT . Ecco Indonesia maka selanjutnya di berikan saran untuk perbaikan atas beberapa kelemahan.

1. Bagi perusahaan

Kurangnya analisa terhadap proses - proses produksi sehingga mengalami keterlambatan pada beberapa proses yang mengakibatkan terjadinya penumpukan dan delay sehingga produksi menjadi terhamabat, sebaiknya perusahan memberikan penghitungan sebelum group atau article yang baru running sehingga di ketahui proses mana yang mengalami hambatan untuk meningkatkan efisien dan efektif dalam perusahaan.

2. Bagi peneliti lain

a. Dalam peneliti yang sama hendaklah peneliti melihat situasi dan kondisi yang ada dalam perusahaan atau instansi tersebut, sehingga dalam melakukan penelitian di harapkan sesuai dengan ke inginan dan manfaat dari peneliti dan bagi perusahaan itu sendiri .

b. Diperlukan penilaian yang lebih mendalam tentang line balancing pada departemen finishing yang ada di perusahaan yang di teliti terutama pada bagian produksi. 


\section{DAFTAR PUSTAKA}

[1] Baroto, Teguh, 2002, Perencanaan dan Pengendalian Produksi. Jakarta: Ghalia Indonesia.

[2] Gasperz, Vincent. 2004, Production Planning And Inventory Control. Jakarta: PT Gramedia Pustaka Utama

[3] Grover, 2001 line balancing dengan metode $R P W$ dan kilbridge wester .

[4] Heizer, Jay dan Barry Render, 2006. Operations Management Buku 2 edisi ke tujuh. Jakarta: Penerbit Salemba Empat.

[5] Halim, A.H. 2003. TI-3122 Perencanaan dan Pengendalian Produksi: Keseimbangan Lintasan. Institut Teknologi Bandung

[6] Indrawan, yayan ,2003 perhitungan line balancing dengan mengunakan metode $R P W$, berbasis single model dalam lintasan produksi .untuk meminimalkan proses produksi

[7] Nasution, H. A 2003, Perencanaan dan Pengendalian Produksi, Institut Teknologi Sepuluh November. 
